(C) The Association for Family Therapy 2008. Published by Blackwell Publishing, 9600 Garsington Road, Oxford OX4 2DQ, UK and 350 Main Street, Malden, MA 02148, USA.

Journal of Family Therapy (2008) 30: 450-464

0163-4445 (print); 1467-6427 (online)

\title{
Non-violent resistance and violence against siblings
}

\author{
Haim Omer, ${ }^{\mathrm{a}}$ Irit Schorr-Sapir ${ }^{\mathrm{b}}$ and Uri \\ Weinblatt ${ }^{\mathrm{c}}$
}

A parent-training approach to the treatment of violence against siblings according to the principles of non-violent resistance was developed aiming at resisting the violence, providing protection to the victims and reducing escalation between the parents and the violent child.

\section{Introduction}

Violence against siblings is probably the most frequent and least recognized form of violence against children (Boney-McCoy and Finkelhor, 1995; Finkelhor, 1995; Finkelhor and Dziuba-Leatherman, 1994; Loeber et al., 1983; Straus and Gelles, 1990). However, in spite of its gravity and prevalence, media coverage of violence against siblings is very small. The disregard extends to the professional literature as well. Thus, the subject of physical and sexual abuse of children by parents was addressed in 7,885 articles in the professional literature in the 1990s, whereas the physical and sexual abuse of children by siblings was addressed only thirty-seven times. ${ }^{1}$ This disregard explains the scarcity of specific programmes for combating sibling violence.

Sharp (1973) has undertaken a systematic presentation of the principles and strategies of non-violent resistance in sociopolitical struggles. In the course of the past ten years, our group has developed (Omer, 2001), manualized (Omer, 2004) and researched (Weinblatt and Omer, 2008) a parent-training programme that translated these principles and strategies to the field of child and adolescent violent and self-destructive behaviours. The programme consists of five to ten

\footnotetext{
a Associate Professor of Psychology, Department of Psychology, Tel-Aviv University, Ramat-Aviv, Israel. E-mail: homer1@bezeqint.net.

b Clinical Psychologist, The Schneider Center for Parent-training, Tel-Aviv, Israel.

${ }^{\mathrm{c}}$ Ph.D.

1 This comparison is based on data from a number of computerized databases.
} 
individual therapy sessions, conducted by a trained clinical psychologist, abetted by up to twice as many phone contacts with a supporter. Over 500 families have been treated to date. This article presents our adaptation of the programme to the special case of violence against siblings.

The transition to non-violent resistance involves a transformation of the power base of the resisting side. In sociopolitical struggles, this is accomplished by a growing awareness and application of the power of togetherness and mobilization of public opinion. A profound accretion in moral power is achieved by the one-sided abandonment of violence. The influence of this moral shift makes itself felt not only on the resisting side, but also on third parties and, sooner or later, on the violent side. A similar transformation occurs in families in which the parents go over to non-violent resistance. The unacceptable power base of naked physical power and humiliating sanctions is abandoned. The parents learn instead to have recourse to the power of parental presence, social support and decided resistance to the child's destructive behaviours.

This change in the parents' power base explains how a doctrine that was originally developed to help the weak resist oppression could be deemed relevant in helping parents. After all, parents are not usually viewed as the powerless side in the parent-child dyad. Parents, however, often feel powerless in the face of children's violent or selfdestructive behaviour, even when they have recourse to physical punishments. Actually, the parents' sense of powerlessness increases the risk of violent outbursts on their side (Bugental et al., 1997). However, once the parents make the transition to non-violent resistance their feelings of helplessness give way to a sense of resourcefulness, support and moral legitimacy, accompanied by a significant reduction in episodes of physical and verbal violence by them, as well as by the aggressive child (Weinblatt and Omer, 2008).

\section{Adapting the principles of non-violent resistance to sibling violence}

Non-violent resistance is a form of fighting

Following on the footsteps of the foremost exponents of non-violent resistance, we talk with the parents openly about the need to fight sibling violence. This fight, however, is deeply different from what is commonly viewed as a 'fight': (1) the parents commit themselves to a 
strictly non-violent and non-humiliating stance; (2) they assume responsibility for their own side in the escalation process; (3) whereas in a more usual kind of fight one's goal is to defeat the adversary, in non-violent resistance the goal is to resist the violence and protect the victim, and (4) the parents fight the child's violence while at the same time attempting to propitiate the positive elements in the relationship. These differences may justify us in characterizing parental nonviolent resistance as a 'constructive' instead of a 'destructive' kind of fighting (Alon and Omer, 2006).

The constructive fighting embodied in non-violent resistance aims at changing the experience of power and powerlessness of the parents, the aggressor and the victim. The parents gradually learn that parental strength has nothing to do with defeating or subjugating the child; the child learns that violent behaviours arouse determined resistance in previously passive victims and bystanders, and the victimized child learns that she or he is no longer alone, unprotected or helpless. Optimally, all participants become resistors: even the perpetrator is invited to participate in resisting his or her own violence.

\section{Increasing parental presence}

One of the chief tools in non-violent resistance is the judicious use of the resistors' personal and bodily presence. Resistance is not implemented by distant, anonymous or impersonal means, but by the readiness of the resistors to bring their personal presence to bear directly on the problem area. In a protest sit-in, for instance, the obstructive bodily presence of the participants is the chief instrument of resistance.

Parental resistance to violence against siblings is manifested first and foremost by an increase in parental presence. Parental presence becomes manifest when parents behave in ways that convey the message, 'I am your mother (father)! You cannot discard me, bribe me, or intimidate me!' Parental presence increases, first and foremost, when the parents spend more time with the children, become more available, and are more aware of the children's doings. They enter the children's rooms more frequently, ask the children more often about the events of the day, and supervise their activities more closely. Parents can also make themselves more present by frequent phone calls. Thus, the parents in our programme are instructed to phone their children (both the perpetrator and the victim) a few times every 
day. In single-parent families we devote special attention to the building of a support net (of friends, relatives and other parents in the programme), which besides supporting the parent's struggle may also back her or him up by becoming present as proxy for the parent when the parent is not directly available.

The profound difference between parental presence and the use of force is one of the central pillars in the programme. Parents who tended in the past to use force are helped to understand that physical punishments are the opposite of a caring manifestation of presence. The required open commitment against all use of violence not only before the therapist but also before the supporting group helps to further inoculate the parents against such outbursts. In this way the programme helps the parents to oppose not only the child's violence against siblings, but also their own contributions to prevalent violent norms in the family.

One form of parental resistance that clearly displays parental presence is a modified form of the political 'sit-in'. The parents enter the room of the aggressor at a time when the aggressor is there, and interpose themselves between the child and the exit. This arrangement is typical of non-violent resistance: the placing of the body signifies the decision not to budge. In the case of single-parent families, someone in the support net should help the parent during the sit-in either in person or on the cellular phone. The parents declare their intent by saying: 'We are not ready to put up with your violence against your brother/sister any more. We will sit and wait for you to come up with a solution that will stop the violence.' The parents are then coached on how to avoid arguments, and withstand provocations. In case of a physical attack by the child, the parents are to defend themselves without hitting back. If the parents think that there is a high probability the child will attack them, they should invite one or two supporters to the house as a preventive measure. The supporters sit outside the room, and the parents say to the child: 'Since we thought you might attack us, we invited so-and-so to come and serve as witnesses in case you do so.' The sit-in is called up when the child makes a constructive proposal, no matter how small. If the child offers no solution, the parents should stay in the room for one hour, after which they leave the room, saying: 'We still haven't found a solution!' The sit-in should be repeated if the violence recurs. Parents have made up to ten sit-ins, but in most families a process of change begins after the initial ones. The sit-in is a significant event not only for the child, but also for the parents. Parents feel they become 
tempered by the sit-in, learning how not to overreact, how to stay silent, and how to persevere. They often express surprise at their own ability to abide by the ordeal.

\section{Preventing escalation}

The systemic literature recognizes two kinds of escalation: complementary (submission increases demands) and symmetrical (hostility engenders hostility) (e.g. Orford, 1986). Non-violent resistance is designed to counter both forms of escalation. Thus the parents of violent children are taught how to resist without becoming involved in destructive power struggles. One way of countering escalation is to follow the principle of delay. The prevalent idea that the parents should react immediately to discipline the aggressive child leads to escalation. The principle of delay, which we illustrate with the therapeutic maxim, 'Strike the iron when it is cold!' allows for arousal to cool down. Parents are told that delay does not mean they are giving in. The parent who witnesses the aggressive act is enjoined to act so as to protect the victim (for instance, by interposing herself between the aggressor and the victim or by taking the victim to another room), but avoid scolding or threatening the aggressor. He or she may say, however, 'I shall think about what happened and return to you later!' This is meant to show that the parent is neither putting up with the violence nor cooperating with the child's invitations to escalate.

Parents are also coached in the avoidance of 'ping-pong' interactions (e.g. repetitive arguments, mutual threats or mutual screaming). Parents often feel they should answer any of the child's contentions. It is helpful to disabuse them of this notion, or tell them that a good answer to a contentious child is to say: 'I am doing this because I must!' If the child complains that this is no answer, the parents can repeat the statement in a lowered tone of voice. This refusal to engage in arguments dampens the escalation and furthers parental selfcontrol.

An additional tool in reducing escalation is the use of mediators. Friends and relatives, who have a good relationship with the perpetrator, can step in as mediators when a direct confrontation between the parent(s) and the aggressive child would increase the risk of escalation. Parents sometimes object to this involvement, arguing that they are strong enough to deal with the problem alone. This parental stance, however, increases the risk of escalation. The involvement of 
mediators is even more relevant for the single parent. Some of the single parents in our programme have reported that phoning a potential mediator served them as a cooling-down step that prevented their own violent outbursts.

\section{Breaking out of isolation}

The isolated, oppressed individual is subject to fear and demoralization. This changes thoroughly when the individual emerges from isolation. In order to tap external sources of support, non-violent resistance must implement a policy of openness. The attempt to keep things secret weakens the parents and helps sustain the child's violent behaviour. A basic rule regarding family violence is that secrecy perpetuates victimization. Enlisting the support of relatives, friends and community workers is thus an essential step in the transition to nonviolent resistance. In the case of single parents, a special effort may be needed to help the parent break out of isolation. The therapist offers help in recruiting potential supporters among members of the extended family, friends or other parents in the project.

Once support has been recruited, the following announcement by the parents to all children may be in place: 'This family will no longer succumb to violence, will no longer let it stay hidden, and will not remain silent when we see it! Every time you see an episode of hitting, humiliating, blackmailing or threatening, you must tell us. We will act resolutely to stop the violence. We will also protect the child who tells us, and not let anything bad happen to her. Besides, here are the telephone numbers of other people who have agreed to help us. You can call them whenever you feel that you need help. It is not tittletattling!' The parents declare that they will demand ongoing reports and will continuously check whether the violence has ceased. The violent child is also invited to take part in the programme by acting against his or her own violence, and by joining in the fight against other displays of violence in the family.

If the parents have doubts as to the truth of the reports, they must tighten their supervision, without assuming an accusing stance towards the suspected aggressor or a minimizing tone towards the child who complains. A parental response to the denials of a child who is being accused of violence can be: 'True or not, we are going to tighten our guard, so as to reduce the chances of such a thing happening!' False complaints do exist, but parental suspicion must not lead to dismissing a complaint that may perhaps be true. An explicit 
statement by the parents that they are increasing their guard (backed, of course, by acts) will reduce the chances of violence without rewarding false complaints.

The parents must encourage the victim to report all violent events, and must help him or her to document them (in writing or on tape). The violent child must be told that there are copies of the documentation, so as to prevent attempts to destroy it. Both the aggressor and the victim should know that the documentation will be made available to a group of supporters who are identified with the cause of stopping the violence.

The parents should ask each of the supporters to address the violent child personally, by phone, letter, fax or e-mail, telling him or her that they have heard a detailed description of the violence. These people should stress their love and care (for the perpetrator as well as for the victim), as well as their belief that the violent child can overcome the problems that are presently occasioning the violence. They may also offer specific help, such as inviting the aggressive child to stay with them for a couple of days, especially if he or she feels about to lose control. It is highly important to search among the supporters for any who have a good relationship with the aggressor, so as to counter the feelings that he or she is being pushed against the wall. These supporters will offer the aggressor help in such situations. However, they will also underscore that the violence must stop.

The supporters must also address the victims, saying that they know about the violence and are committed to helping them and their parents put an end to it. The supporters should give the victims their phone numbers and make sure they were taken down correctly. The supporters are encouraged to keep in constant contact (in person and by phone) with the perpetrator, the victims and the parents.

Exposing the secret and including outside people often triggers strong emotional reactions in the perpetrator, who may accuse the parents of betrayal, threaten to stop talking to them or to run away from home. Therefore the parents should tighten their supervision in the wake of their decision to go open. They should also prepare to withstand the child's negative reactions without being provoked into escalation.

\section{Involving the victim in the resistance programme}

Giving testimony can be a highly significant act of resistance. In extreme oppressive situations, this may be the only act of resistance 
that is available to the victims. The value of testimony for the oppressed has been demonstrated by the victims of the military dictatorship in Chile, of racial apartheid in South Africa, or within the starving confines of the Warsaw Ghetto. Testimony is quite different from therapeutic disclosure: the latter is almost always a private event, whereas testimony has a public dimension. In a therapeutic programme this public dimension should be underlined, for instance, by having the victims' testimony tape-recorded or written down, and by asking for their permission to circulate it to other victims, potential supporters or staff members. In our programme we also institute public readings of the testimony that, besides the child and the parents, may include supporters or members of the treatment staff.

The victims are also asked for ideas on how to develop better ways of self-protection. They should participate in making plans for various eventualities, for instance, deciding who they should phone if the parents are away, where they could find shelter, or how they could help one another. The children's resistance steps should be acknowledged by the parents and by the supporters. A letter from the therapist may also contribute to convey acknowledgement and appreciation. In our programme such letters, summing up the children's efforts and achievements in resistance, are often treasured by the child.

\section{Reconciliation steps}

Leaders like Gandhi and Luther King did not settle for the absence of violence alone: they demanded from themselves and from their followers that the acts of resistance be accompanied, as far as humanly possible, by real respect for the adversary. Acts of respect and reconciliation strengthen the positive voices on the opposing side. Parents often report that initiating reconciliation moves (e.g. messages of respect and appreciation, symbolic treats, proposing joint activities, or acknowledging past offences), far from weakening them, strengthened their determination to resist. The parents related that the reconciliation gestures released them from the role of 'the bad guys', allowing them not to feel guilty in their resistance steps.

Reconciliation gestures also convey the message that the violent child belongs fully to the family. This is especially important in view of the fact that the mobilization of the whole family and of external supporters against the violence may arouse feelings of exclusion in the 
child. Reconciliation gestures are not a prize that is made conditional on good behaviour, but free manifestations of love and care. The child is not even expected to accept the gesture: in case of refusal, the parent(s) may say: 'I am doing this because I am your mother/father, and because I love you. But I can only do my side, and cannot make you accept it!' In our experience, reconciliation gestures are also effective when they are met by a show of refusal by the child.

One of the objections parents raise to reconciliation gestures is that they convey weakness. This feeling reflects the parents' tendency to think in terms of 'Who's the boss?' On these lines, anything that does not convey toughness conveys weakness. However, as they gain experience in non-violent resistance, the parents learn to differentiate between reconciliation and submission.

\section{Case study}

Joe and Rachel came to the Parents' Guidance Centre because of their son's (David, aged 15) violent behaviour. He was also highly impulsive in other respects and had recently climbed on to the roof of their home and threatened suicide. David had already been seen by two psychiatrists, who had prescribed medication, but after a short while he had refused to take it. The parents explained that David's sisters, Sara, Shira and Judith $(17,10$ and 5), lived in fear of him and were obliged to fulfil his every whim. He seemed to be always on the lookout for someone to harass. His moods changed rapidly and his outbursts were totally unpredictable. He would suddenly start to throw things about, and kick doors, chairs and cupboards. If he found fault with his mother's cooking, he would throw the food on the floor or throw the beverage he was drinking in her face. He would beat up his sisters and destroy their property. Sometimes he would stay the whole night away from home. He carried a knife, which he sometimes brandished before his sisters and mother in a kind of nonspecific super-threat. He would also mumble threats, as if to himself. The parents lived in fear that he would hurt the girls or commit suicide, and found no alternative but to give in to him and try their best to calm his temper.

Rachel said that the girls were totally miserable and complained that Joe was unhelpful. She blamed him as being only a provider and not really a father. Joe criticized her for being 'too soft' and for failing to hold her own not only against David but also against the girls. Rachel countered that she was mentally and physically exhausted: 
'Sometimes I want to open the window and start screaming! I feel I have to do all in my power just to keep sane!' Sometimes she would lie down early in the day, feeling she did not want to get up again. The therapist thought that Rachel was clinically depressed. Surprisingly, in spite of the hardships and the mutual complaints, Rachel and Joe had a positive relationship with each other. Joe softened up towards Rachel during the session, and Rachel said that they often felt very close. The constant attrition with David, however, left very little space for them to enjoy their togetherness.

The treatment began with a detailed explanation of the principles and techniques of non-violent resistance. This was followed by the recruitment of a support net. Fortunately, Rachel and Joe had many friends and relatives whom they could approach. Thirteen helpers turned up at the session that was devoted to the support net. Among the potential helpers there were two people who had a good relationship with David: Rachel's eldest brother, who was present at the meeting, and Joe's adoptive father, who lived abroad. A written summary of the session was sent to Joe's adoptive father. In this manner he was recruited into the support net in spite of the distance. These two people would not only give the parents support, but also serve as mediators, helping to reduce David's feelings of isolation. Rachel's brother also offered to take David over to stay with him on weekends and holidays in the coming months.

The therapist made a home visit to interview the sisters. Sara and Shira corroborated the parents' description. Sara felt the situation was completely hopeless. She was sure that David could not control himself. There was no use asking for help or calling the police. She believed that she was often to blame, because she answered back and inflamed David's anger. Shira cried for a good part of the interview. She was horribly afraid when David screamed, when he hit them and, most of all, when he brandished his knife. She was also afraid that David would be taken out of the house by force. She believed he would then kill himself and the family would be destroyed. Judith stayed out of the room during the interview. The parents and Sara explained to her later in the day what they were going to do to stop David frightening and beating them.

The girls gradually warmed to the idea of resistance. Initially, they said they would not be able to call the helpers or run for safety when they were attacked, because David would not let them go or would punish them badly afterwards. However, the suggestion that in such a case the sister that was not under direct attack could phone the 
helpers and that the helpers would make sure that David would not punish them (for instance, by staying in the house until the situation was fully under control) brought a first glimmer of hope for the girls. The possibility of the two of them building a common front with the help of external supporters proved highly attractive to them. After a while, they started raising ideas about how they could run to the neighbours for shelter, and how they could hide when David began threatening. The idea of keeping a diary that would be read weekly in a joint session with the parents and circulated among the helpers met with a very positive response. The therapist phoned a few of the supporters while still in the girls' room. Three of them promised to visit them and discuss the details with them on the same evening. By the end of the day the sisters had talked by phone with most of the helpers, and had concealed the list with all their names and phone numbers in two different hiding places. The helpers promised to call them regularly, and to do their best to come when they were called. They also promised that they would not hurt David or allow anyone to take him away from the family against his and the parents' will. By the end of the week Sara and Shira had stopped being a couple of lonely, helpless and terrorized girls, and had become active members in a programme of resistance that gave them a beginning sense of worth and strength.

The therapist and the parents prepared an open announcement to David that the parents were going to resist his violence, and to get help from friends and relatives in their effort. The parents were very anxious about David's reaction to the announcement. They decided to have a couple of helpers in the house at the time, so as to reduce the risk of a violent response. David was stunned and asked if he would be sent to gaol. They explained that the helpers were not there to send him to gaol, but to help him and the family to overcome the difficulties. The parents mentioned also some of the other people who would be involved. Later in the evening, David received a call from his adoptive grandfather, telling him that the whole family had decided never to send him away, not just to gaol, but anywhere else. However, the grandfather added that David's violence against his sisters and his mother would have to stop. Surprisingly, for the parents, David had no major outburst during or after the sit-in. The following day, he surprised them even more by bringing a bag of sweets for his sisters.

After a few days of unusual quiet, David began screaming at his sisters and his mother. When he started to break Sara's pencils and 
throw the broken pieces at her, the mother intervened, took Sara into her own room, locked the door and phoned the father and two helpers. One of them, a next-door neighbour, arrived within minutes. David shut himself in his room and refused to answer. The father and the other helper phoned and asked to talk to David, but to no avail. Rachel wrote a message to David, and slipped it under his door. David picked up the message but did not respond. In the evening, Joe, Rachel and two other helpers came into David's room and staged a sitin, declaring they would wait until David came up with an idea about how to stop the violence. David raved, saying, "they would never defeat him'. The father waited for him to stop screaming, and then said quietly: 'We know we cannot defeat you. But we will resist the violence, because we have no choice.' About half an hour into the sitin, David surprised his parents by saying he wanted to take medication. The parents called off the sit-in and told David that his proposal would be given a chance. He met with the psychiatrist and started taking medication on a regular basis. Gradually, the violent episodes became less and less frequent and extreme. At this time the therapy started to focus on some of David's other problems, such as his irregular school attendance and his tendency to disappear from home and come back late at night or not at all.

By the end of the treatment Rachel no longer seemed depressed. She now impressed the therapist as being a very warm, perceptive and intense person. Joe said he had almost forgotten what Rachel could be like. An interview with the girls showed that both felt more secure than ever before. Shira said that what had happened was a miracle, as they had started to live again and had won their brother back after losing all hope of improvement. Sara no longer felt she was to blame when David flared up. The family was advised to keep updating the helpers on the situation. Two follow-up sessions, after one and three months, were scheduled. At these sessions the parents reported on their continued contact with the helpers. The physical violence had disappeared. David's school attendance and nightly absences were considerably improved. David still had occasional temper tantrums in which he yelled and cursed his mother and sisters, but the level of anxiety and victimization in the family was incomparably lower.

\section{Discussion}

A good treatment for sibling violence should be able to fulfil a number of requirements: (1) to provide security for the victims; (2) to counter 
their feelings of helplessness and of low self-esteem; (3) to lead to minimum escalation; (4) to be acceptable and practicable to the majority of parents, and (5) to help preserve and propitiate the positive elements in the relationship with the aggressive child.

1 This programme focuses immediately on the issue of security: the parents are not only required to increase their presence and supervision, but are also specifically trained how to do so. They also receive intensive support from relatives and friends. The mobilization of the helpers greatly increases the victims' and the parents' sense of security, often in a matter of days.

2 Non-violent resistance is one of the most potent antidotes against feelings of helplessness and of low self-esteem. Our interviews ${ }^{2}$ with the victimized siblings confirmed that this is precisely how they feel. The change from pre- to post-treatment in their sense of security and self-esteem was very pronounced. Their sense of trust in the parents' ability to protect them grew markedly. The programme completely changed their feelings that their suffering was hidden from view, meaningless and irreparable.

3 Non-violent resistance is to our knowledge the only treatment programme that places escalation at the very centre of attention. In fact, non-violent resistance consists in much more than the mere abstinence from violence, involving also strict self-control regarding provocative speech and gestures, voluntary relinquishment of dominant positions ('I am the boss!'), continuous management of emotional arousal ('Hit the iron when it is cold!'), and a permanent readiness to involve mediators in order to defuse explosive situations. In addition, non-violent resistance is often accompanied by reconciliation gestures that aim specifically at reducing escalation and widening the base of the relationship.

4 The acceptability of the programme to parents is shown by the very low drop-out rates that were observed (Weinblatt and Omer, 2008). Less than 10 per cent of the parents left the treatment before the end (to our knowledge this is the lowest rate in the literature). More than 85 per cent of the participants were able to perform the chief steps in the programme (announcing their decision to fight the violence non-violently, staging sit-ins, recruiting the help of a

${ }^{2}$ All victimized siblings receive a semi-structured interview according to the lines proposed by Caffaro and Conn-Caffaro (1998) at the beginning and end of treatment. 
support network, helping the victims to document their sufferings, and initiating reconciliation moves).

6 A comparative outcome study reported a clear improvement in the relationship between the parents and the aggressive child (Weinblatt and Omer, 2008). A check-list of positive and negative interactions was administered weekly to the parents during the treatment, showing a rise in positive interactions and a decrease in negative ones. Interviews with a subsample of aggressors disclosed that more than half of these children reported on improvements in their relationship with their parents (only one out of fifteen children reported a worsening situation). Last but not least: the victims reported a clear improvement in their relationship with the aggressor.

However, non-violent resistance has some clear limitations. Although it helps protect the family against violence and reduce escalation, help is often still needed to deal with the problems that may have propitiated the violence. Factors such as problematic peer involvement, school failure, substance abuse and highly irregular life routines may have to be addressed in the sequel. In our programme, parents who succeeded in reducing not only the child's but also their own violent outbursts are helped to deal with these other risk factors as well. Parental presence is a wider concept than non-violent resistance. In fact, non-violent resistance is only a first step in the direction of helping the parents become more present and caring. An important caveat: the parents who come to our programme come of their own will (for instance, after hearing a presentation of the approach in the child's school). These parents, although occasionally suffering from uncontrolled outbursts, are not the kind of highly violent and abusive parents who may, for instance, be referred to treatment by a court ruling. We believe that for such abusive parents a more intensive approach, involving also non-violent resistance against their own violence and abuse, would be necessary.

\section{References}

Alon, N. and Omer, H. (2006) The Psychology of Demonization: Promoting Acceptance and Reducing Conflict. Mahwah, NJ: Lawrence Erlbaum Associates.

Boney-McCoy, S. and Finkelhor, D. (1995) Psychosocial sequelae of violent victimization in a national youth sample. Journal of Consulting and Clinical Psychology, 63: 726-736. 
Bugental, D. B., Lyon, J. E., Krantz, J. and Cortez, V. (1997) Who's the boss? Accessibility of dominance ideation among individuals with low perceptions of interpersonal power. Journal of Personality and Social Psychology, 72: 1297-1309.

Caffaro, J. V. and Conn-Caffaro, A. (1998) Sibling Abuse Trauma. New York: Haworth Press.

Finkelhor, D. (1995) The victimization of children: a developmental perspective. American Journal of Ortopsychiatry, 63: 177-193.

Finkelhor, D. and Dziuba-Leatherman, J. (1994) Victimization of children. American Psychologist, 49: 173-183.

Loeber, R., Weissman, W. and Reid, J. B. (1983) Family interactions of assaultive adolescents, stealers and nondelinquents. Journal of Abnormal Child Psycholgy, 11: $1-14$.

Omer, H. (2001) Helping parents deal with children's acute disciplinary problems without escalation: the principle of non-violent resistance. Family Process, 40: $53-66$.

Omer, H. (2004) Non-violent Resistance: A New Approach to Violent and Selfdestructive Children. Cambridge: Cambridge University Press.

Orford, J. (1986) The rules of interpersonal complementarity: does hostility beget hostility and dominance, submission? Psychological Review, 93: 365-377.

Sharp, G. (1973) The Politics of Nonviolent Action. Boston, MA: Extending Horizons Books.

Straus, M. R. and Gelles, R. J. (1990) Physical Violence in American Families: Risk Factors and Adaptations to Violence in 8,145 Families. New Brunswick, NJ: Transaction.

Weinblatt, U. and Omer, H. (2008) Nonviolent resistance: a treatment for parents of children with acute behavior problems. Journal of Marital and Family Therapy, 34: 75-92. 